\title{
Lymphohaematopoeitic cancer mortality among workers with benzene exposure
}

\author{
J J Collins, B Ireland, C F Buckley, D Shepperly
}

Occup Environ Med 2003;60:676-679

See end of article for authors' affiliations

Correspondence to: Dr J J Collins, Dow Chemical, Building 1803 Midland, Michigan 48674, USA iicollins@dow.com

Accepted 4 August 2002
Lymphohaematopoeitic cancer mortality was examined among 4417 workers at a chemical plant by cumulative and peak benzene exposure. There was little evidence of increasing risk with increasing cumulative exposure for all leukaemias or acute non-lymphocytic leukaemias (ANL), or the other lymphohaematopoeitic cancers with the exception of multiple myeloma. For multiple myeloma, the SMRs were $1.1(95 \% \mathrm{Cl} 0.3$ to 2.5$)$ in the non-exposed group, $1.4(95 \% \mathrm{Cl} 0.2$ to 5.1$)$ in the $<1$ ppm-years, $1.5(95 \% \mathrm{Cl} 0.2$ to 5.4$)$ in the $1-6$ ppm-years, and 2.6 (95\% $\mathrm{Cl} 0.7$ to 6.7$)$ in the $>6$ ppm-years group. We found no trends by peak exposures for any of the cancers. However, when peak exposures over $100 \mathrm{ppm}$ for 40 or more days were considered, the observed number of all leukaemias (SMR $=2.7$, $95 \% \mathrm{Cl} 0.8$ to 6.4 ), $\mathrm{ANL}$ (SMR $=4.1,95 \% \mathrm{Cl} 0.5$ to 14.9 ), and multiple myeloma (SMR $=4.0,95 \%$ $\mathrm{Cl} 0.8$ to 11.7$)$ were greater than expected. While the observed number of deaths is small in this study, the number of peak exposures greater than $100 \mathrm{ppm}$ to benzene is a better predictor of risk than cumulative exposure. The dose rate of benzene and a threshold for exposure response may be important factors for evaluating lymphohaematopoietic risk.
$E^{2}$ xposure to high levels of benzene increases the risk of acute non-lymphocytic leukaemias (ANL). ${ }^{1-4}$ Some studies indicate that multiple myeloma, Hodgkin's lymphoma, non-Hodgkin's lymphoma, chronic myeloid leukaemia, chronic lymphocytic leukaemia, and various myelodysplastic syndromes may also be related to benzene exposure..$^{5-9}$ Studies of workers exposed to low benzene levels have been null or reported only slightly increased rates of ANL or all leukaemias..$^{10-18}$ The dose rate of benzene, or the exposure concentration received over time, appears important for assessing cancer risk in experimental systems. Specifically, some argue that a critical concentration must be present before cancer risk is increased. ${ }^{19}{ }^{20}$ Most previous studies of benzene workers have used cumulative exposure independent of concentration to assess risk. We examine lymphohaematopoeitic cancers in the present study to determine the effects of low cumulative benzene exposure and short term exposure peaks. The plant that we studied was included in a previous industry wide benzene study. ${ }^{13}$ The cancer rates of the workers at this plant have been reported previously, but we extend the vital status follow up, add female workers, and compare effects of different benzene dose rates. ${ }^{17}$

\section{SUBJECTS AND METHODS}

We included all hourly workers beginning employment between 1940 and 1977 at the Solutia plant, previously Monsanto, in Sauget, Illinois. Person time accumulation began on hire date and ended at the earliest of study termination date (31 December 1997), the last day worked if lost to follow up, or the date of death. The study cohort included 4172 men and 245 women ascertained from work records and reports to the Internal Revenue Service. Vital status follow up was completed for 4352 (99\%) workers, of which 2431 (56\%) were deceased. We obtained death certificates for all but 27 (1\%) decedents. We included deceased workers for whom we lacked a death certificate in the all-cause mortality analysis.

\section{Exposure assessment}

The benzene using departments at the plant were nitrobenzene, phenol, chlorobenzene, muriatic acid, and alkylbenzene production. Only the chlorobenzene and muriatic acid departments were operational when collection of personal exposure data began in 1980. However, some area sampling was available for all departments. We used the history of process changes, area sampling levels, individual level exposures (that is, 1090 personal time weighted average eight hour benzene exposures and 247 personal short term exposure levels) and the plant's industrial hygienist's (CFB) judgement to estimate exposures. Most exposures stratified by time, department, and job had to be estimated without relevant personal exposure data.

We estimated continuous exposures as eight hour time weighted averages using categories $<1,1-10$, and 11-50 ppm. We were unable to estimate potential for continuous benzene exposure for maintenance jobs since exposure to benzene is intermittent and highly variable. We also estimated the number of days for which a 15 minute exposure excursion in excess of 100 ppm was likely. We estimated potential for peak exposures for all job types.

We cumulated individual daily exposure and divided the exposure categories into three groups used in the previous study: less than 1 ppm-year, 1-6 ppm-years, and greater than 6 ppm-years. ${ }^{17}$ Cumulative exposures ranged from 0.1 ppmyears to 632 ppm-years with a median of 3 ppm-years. Similarly, we cumulated the number of days with peaks into categories used in the previous study: no day over $100 \mathrm{ppm}$, less than 7 days, $7-40$ days, and more than 40 days. ${ }^{17}$ The number of days with peak exposures greater than $100 \mathrm{ppm}$ ranged from 1 to 2590 with a median of 22 days. Most job types in the plant had no potential for peak exposures over 100 ppm.

\section{Statistical analysis}

We compared worker death rates with rates for the population of Illinois. We calculated standardised mortality ratios (SMRs) and $95 \%$ confidence intervals (CI) using the Fisher exact

Abbreviations: $\mathrm{ANL}$, acute non-lymphocytic leukaemia; $\mathrm{Cl}$, confidence interval; SMR, standardised mortality ratio 


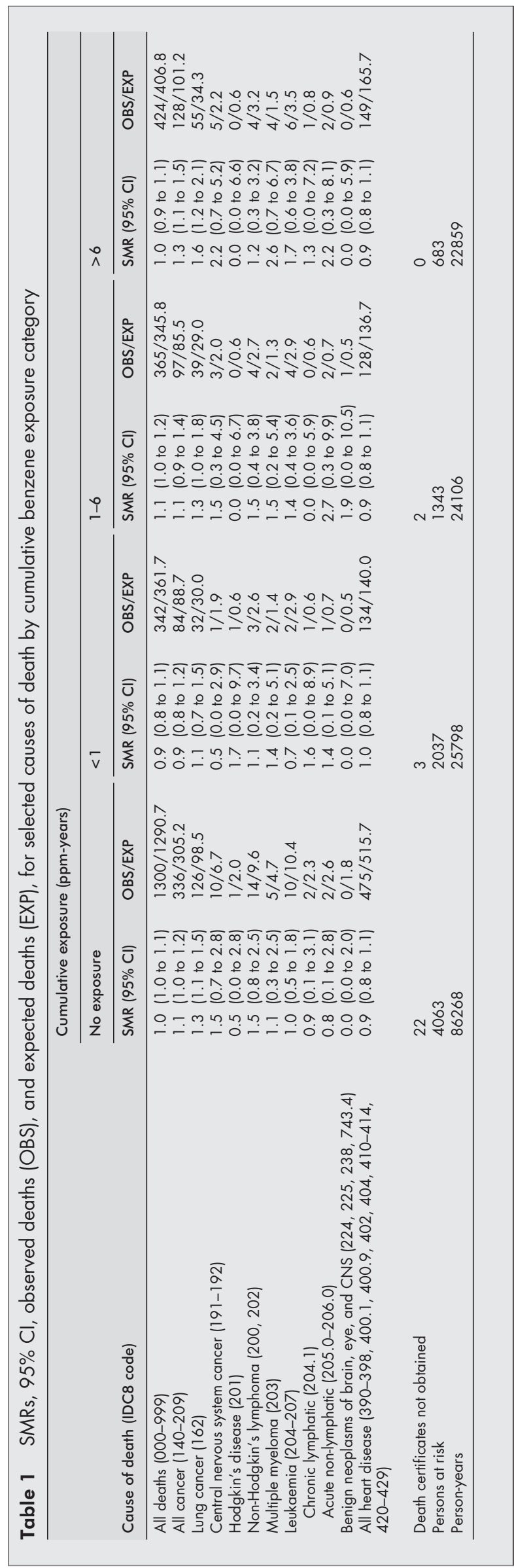

method. ${ }^{21}{ }^{22}$ Study conduct followed the guidelines given by the Chemical Manufacturer's Association. ${ }^{23}$

\section{RESULTS}

Table 1 presents SMRs for workers in cumulative benzene exposure categories for selected causes of death. Total mortality SMRs for the no exposure category is 1.0 (95\% CI 1.0 to 1.1 ), for < $<$ ppm-years is 0.9 (95\% CI 0.8 to 1.1 ), for $1-6$ ppm-years is 1.1 (95\% CI 1.0 to 1.2 ), and for $>6$ ppm-years is 1.0 (95\% CI 0.9 to 1.1$)$. The all cancer SMRs range from 0.9 (95\% CI 0.8 to 1.2 ) in 1 ppm-years category to 1.3 (95\% CI 1.1 to 1.5 ) in the $>6$ ppm-years exposure category. SMRs greater than one for central nervous system cancers and lung cancer were seen among exposed and unexposed workers. The SMRs for all leukaemias were 1.0 (95\% CI 0.5 to 1.8 ) for no exposure, 0.7 (95\% CI 0.1 to 2.5 ) for < 1 ppm-years, 1.4 (95\% CI 0.4 to 3.6) for $1-6$ ppm-years, and 1.7 ( $95 \%$ CI 0.6 to 3.8) for the $>6$ ppm-years. ANL SMRs show a similar trend by exposure category, but chronic lymphatic leukaemia does not. The SMRs for multiple myeloma increase with cumulative exposure category, but neither Hodgkin's disease nor non-Hodgkin's lymphoma shows a similar trend.

Table 2 presents SMRs for workers in short term peak benzene exposure categories. No increasing trend with peak benzene exposures is present for any of the causes of death examined. However, SMRs in the $>40$ days with peak exposures over $100 \mathrm{ppm}$ are 4.0 (95\% CI 0.8 to 11.7) for multiple myeloma, 2.7 (95\% CI 0.8 to 6.4) for all leukaemias, 4.1 (95\% CI 0.5 to 14.9 ) for acute non-lymphatic leukaemia, 1.8 (95\% CI 0.4 to 5.1 ) for non-Hodgkin's lymphoma, and 1.6 (95\% CI 1.1 to 2.3 ) for lung cancer. While not shown in either table, no deaths from anaemia (ICD-8, 280-289) were found among benzene exposed workers.

Of the 22 leukaemia deaths, 15 occurred among workers with benzene exposure (12 with cumulative exposure, four with cumulative and peak exposure, and three with only peak exposure). The SMR for all cumulative exposed workers is 1.3 (95\% CI 0.7 to 2.3 ) and the SMR for all peak exposed workers is 1.8 (95\% CI 0.7 to 3.6). SMRs for leukaemia by year of hire for all benzene exposed workers were 0.9 (95\% CI 0.4 to 1.7) for hire year $1940-49,1.6$ (95\% CI 0.4 to 4.1 ) for hire year 1950-59, and 3.2 (95\% CI 0.7 to 9.4) for hire year 1960-77. The SMRs for interval from onset of exposure for exposed workers were 1.3 (95\% CI 0.0 to 7.0 ) for < 10 years, 2.2 (95\% CI 0.5 to 6.5) for $10-19$ years, and 1.1 (95\% CI 0.6 to 1.9 ) for $20+$. Ten of the 13 deaths from multiple myeloma occurred among workers with benzene exposure (eight with cumulative exposure, two with cumulative and peak exposure, and two with only peak exposure). Six occurred among workers hired in $1940-49($ SMR $=1.3,95 \%$ CI 0.5 to 2.9$)$, three among workers hired in 1950-59 (SMR $=2.8,95 \%$ CI 0.6 to 8.0$)$, and one among workers hired 1960 or later $(\mathrm{SMR}=2.7,95 \% \mathrm{CI} 0.1$ to 15.1). All 10 deaths from multiple myeloma occurred 20 or more years after first exposure ( SMR $=1.8,95 \%$ CI 0.9 to 3.3 ).

\section{DISCUSSION}

Unlike the Pliofilm worker study, we found little evidence of increasing leukaemia or ANL risk with increasing cumulative exposure to benzene. ${ }^{3}$ However, there were more leukaemias ( 5 observed, 1.8 expected) and more ANL ( 3 observed, 0.8 expected) than expected when peak exposures over $100 \mathrm{ppm}$ for 40 or more days were considered. There was little or no increased risk in any of the lower exposure categories for these cancers. The pliofilm worker study also found an increased risk of multiple myeloma among benzene workers, but this increased risk was not related to cumulative exposure. We also observed increased rates of multiple myeloma among our benzene workers and there is an indication of increasing risk with increasing cumulative exposure. However, we also observed increased rates of multiple myeloma among workers 


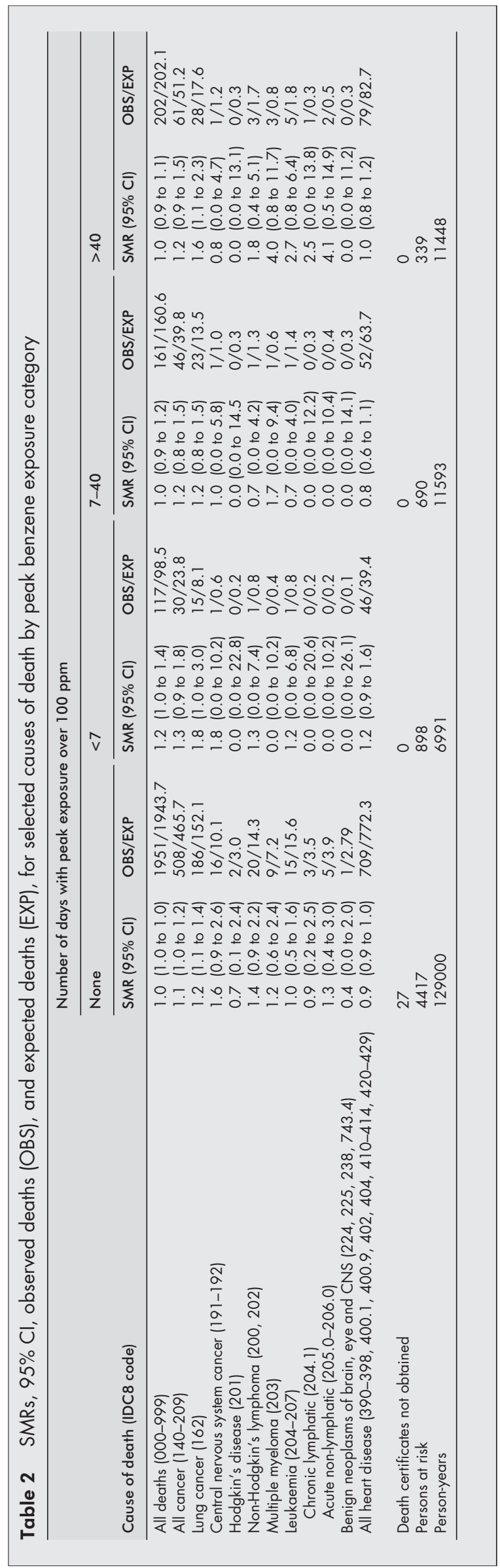

with 40 or more days of peak exposures exceeding 100 ppm, with little indication of increased risk in the other categories. With the exception of leukaemias, particularly acute nonlymphocytic leukaemia, and multiple myelomas, there is little evidence that any of the other lymphohaematopoietic cancers were related to either cumulative dose or number of peaks.

Cancer risk assessment for benzene has assumed a cumulative relationship between exposure and risk, independent of the concentration. ${ }^{24-28}$ An alternative view is that there is a threshold concentration below which no significant bone marrow toxicity occurs and thus there is no increased leukaemia risk. ${ }^{19}{ }^{20}$ Further, exposure intermittency may also be important for understanding benzene induced myelotoxicity. ${ }^{192} 29$ For example, in animal models, multiple high exposure intervals interrupted by several days are more effective in producing bone marrow suppression than repeated daily administrations. ${ }^{19}$ While our study is small and has lower cumulative exposures that the Pliofilm worker study, we find that a high number of peak exposures to benzene appeared to be a better predictor of ANL risk than cumulative exposure. Since the Pliofilm worker study did not estimate exposure peaks, it is not possible to directly compare our findings. However, if concentration is important for evaluating increased risk, the use of cumulative exposure alone may obscure the true risk from benzene exposure. Recently, the Pliofilm worker study was re-evaluated using an indicator of exposure concentration rather than cumulative exposure and the authors concluded that increased leukaemia risk occurs with a minimum concentration between 20 and $60 \mathrm{ppm}$ of benzene, arguing for a threshold of exposure. This conclusion is consistent with our findings and an indication that dose rate and a threshold need consideration in studies of benzene workers for leukaemia risk.

We also observed increased risk of all cancers among both unexposed and exposed workers. Death from lung cancer, central nervous cancer, and non-Hodgkin's lymphoma exceeded expected numbers for exposed and unexposed workers. However, these cancers were not associated with either cumulative or peak benzene exposures and thus probably not related to benzene exposure.

There are several limitations that we considered in evaluating these results. Exposure estimation was difficult for the 1940s and 1950s because little information was available. We assigned our highest exposures to jobs during that time, but exposures could have been much higher given the greater potential for upset conditions. These uncertain exposure estimates could have caused misclassification of exposures that could have biased our estimates of risk associated with either cumulative or peak exposures. Also, many other exposures were possible in this plant during the study dates, although no other known or suspected leukaemogen was used or made in this plant. Smoking has been related to increased leukaemia risk. ${ }^{30}$ We had no information on smoking status of our workers, but given the magnitude of the leukaemia risk among exposed workers, we think it unlikely that smoking is an important confounder.

There is continuing debate about whether low benzene exposure increases risk of multiple myeloma and all types of leukaemia, or just ANL. ${ }^{31}$ Our study found increased rates of ANL and multiple myeloma at benzene concentrations greater than $100 \mathrm{ppm}$. High and intermittent benzene exposure was related to the highest risk. Our findings were limited by imprecision, and the potential for exposure and disease misclassification. Nevertheless, the dose rate appeared important for evaluating lymphohaematopoietic cancer risk in our study.

\section{ACKNOWLEDGEMENTS}

Solutia supported this study. We acknowledge the valuable contributions of data management from Diane Bowens, programming support 
from Susan Riordan, death certificate coding from Carole Penn and Carolyn Watkins, mortality follow up from Phyllis Korte, and the plant support from industrial hygienists Tom Blank and Janet Noble, and from Pat Schaeffer.

\section{Authors' affiliations}

J J Collins, D Shepperly, Solutia, 575 Maryville Centre Drive, St Louis, MO 63141, USA

B Ireland, St Louis University

C F Buckley, Retired from Monsanto

\section{REFERENCES}

1 Aksoy M, Erdem S, DinCol G. Leukemia in shoe-workers exposed chronically to benzene. Blood 1974:44:837-41.

2 Vigliani EC, Forni A. Benzene and leukemia. Environ Res 1976;11:122-7.

3 Rinsky RA, Young R, Smith AB. Leukemia in benzene workers. Am J Ind Med 1981;2:217-45.

4 IARC. Evaluation of the carcinogenic risk of chemicals to humans, Vol 29. Benzene. Lyon: International Agency for Research on Cancer, 1982.

5 Aksoy M. Different types of malignancies due to occupational exposure to benzene: a review of recent observations in Turkey. Environ Res 1980;23:181-90.

6 Decoufle P, Blattner WA, Blair A. Mortality among chemical workers exposed to benzene and other agents. Environ Res 1983;30:16-25.

7 Goldstein B. Is exposure to benzene a cause of human multiple myeloma? Ann N Y Acad Sci 1990;609:225-34.

8 Yin S-N, Hayes RB, Linet MS, et al. A cohort study of cancer among workers exposed to benzene in China: overall results. Am J Ind Med 1996;29:227-35.

9 Hayes RB, Yin S-N, Dosemeci M, et al. Benzene and the dose-related incidence of hematologic neoplasms in China. J Natl Cancer Inst 1997:89:1065-71.

10 Ott MG, Townsend JC, Fishbeck WA, et al. Mortality among individuals occupationally exposed to benzene. Arch Environ Health 1978;33:3-10.

11 Tsai SP, Wen CP, Weiss NS, et al. Retrospective mortality and medical surveillance studies of workers in benzene areas of refineries. J Occup Med 1983;25:685-92.

12 Bond GG, McLaren EA, Baldwin CL, et al. An update of mortality among chemical workers exposed to benzene. Br J Ind Med 1986;43:685-91.

13 Wong $\mathrm{O}$. An industry wide mortality study of chemical workers occupationally exposed to benzene. II. Dose response analyses. $\mathrm{Br} J$ Ind Med 1987:44:382-95.

14 Paxton MB, Chinchilli VM, Brett SM, et al. Leukemia risk associated with benzene exposure in the pliofilm cohort I. Mortality update and exposure distribution. Risk Anal 1994;14:147-54.
15 Schnatter AR, Armstrong TW, Nicolich M, et al. Lympohaematopoietic malignancies and quantitative estimates of exposure to benzene in Canadian petroleum distribution workers. Occup Environ Med 1996;53:773-81.

16 Rushton L, Romaniuk H. A case-control study to investigate the risk of leukemia associated with exposure to benzene in petroleum marketing and distribution workers in the United Kingdom. Occup Environ Med 1997;54:152-66.

17 Ireland B, Collins JJ, Buckley CF. Cancer mortality among worker with benzene exposure. Epidemiology 1997;8:318-20.

18 Wong O, Trent L, Harris F. Nested case-control study of leukemia, multiple myeloma, and kidney cancer in a cohort of petroleum workers exposed to gasoline. Occup Environ Med 1999;56:217-21.

19 Irons RD, Heck HA, Moore BJ, et al. Effects of short-term benzene administration on bone marrow cell cycle kinetics in the rat. Toxicol Appl Pharmacol 1979;51:399-409.

20 Schnatter AR, Nicolich M, Bird MG. Determination of leukemogenic benzene exposure concentrations: refined analysis of the pliofilm cohort. Risk Anal 1996;16:833-9.

21 Marsh GM, Preininger M. OCMAP: a user-oriented occupational cohort mortality analysis program. Am Stat 1980;34:245.

22 Rothman KJ, Boice JD. Epidemiologic analysis with a programmable calculator. NIH Publication No. 79-1649. Washington, DC: Government Printing Office, 1979:30-1.

23 The Chemical Manufacturers Association's Epidemiology Task Group. Guidelines for good epidemiology practices for occupational and environmental epidemiologic research. J Occup Med 1991;33:1221-9.

24 Albert RE. Carcinogen Assessment Group's final report on population risk to ambient benzene exposures. Publication no. EPA-450/5-80-004. Research Triangle Park, NC: US Environmental Protection Agency, Office of Air Quality Planning and Standards, 1979.

25 White MC, Infante PF, Chu KC. A quantitative estimate of leukemia mortality associated with occupational exposure to benzene. Risk Anal 1982;2:195-204

26 Rinsky RA, Smith $A B$, Hornung R, et al. Benzene and leukemia: an epidemiologic risk assessment. N Engl J Med 1987;316:1044-50.

27 Health Council of The Netherlands. Carcinogenic risk assessment of benzene in outdoor air. Regul Toxicol Pharmacol 1989;9:175-85.

28 Swaen GMH, Meijers JMM. Risk assessment of leukemia and occupational exposure to benzene. BrJ Ind Med 1989:46:826-30.

29 Austin H, Delzell E, Cole P. Benzene and leukemia: a review of the literature and a risk assessment. Am J Epidemiol 1988;127:419-39.

30 Austin H, Cole P. Cigarette smoking and leukemia. J Chron Dis 1986;39:417-21.

31 Landrigan PJ. Benzene and blood: one hundred years of evidence. Am $J$ Ind Med 1996;29:225-6.

32 Wong $\mathrm{O}$. Risk of acute myeloid leukemia and multiple myeloma in workers exposed to benzene. Occup Environ Med 1995;52:380-4 